\title{
Predictors of Obstructive Sleep Apnea Risk among Blacks with Metabolic Syndrome
}

\author{
Rogers $\mathrm{A}^{1}$, Ravenell $\mathrm{J}^{1}$, Donat $\mathrm{M}^{2}$, Sexias $\mathrm{A}^{1}$, Ogedegbe $\mathrm{C}^{4}$, McFarlane $\mathrm{SI}^{3}$, and Jean-Louis $\mathrm{G}^{* 1}$ \\ ${ }^{1}$ Center for Healthful Behavior Change (CHBC), Division of Health and Behavior, Department of Population Health, \\ New York University Medical Center, New York, USA \\ ${ }^{2}$ Department of Family Medicine, SUNY Downstate Medical Center, New York, USA \\ ${ }^{3}$ Division of Endocrinology, Department of Medicine, State University of New York-Downstate Medical Center, \\ Brooklyn, USA \\ ${ }^{4}$ Department of Emergency Medicine, Hackensack UMC, Hackensack, NJ, USA
}

${ }^{*}$ Corresponding author: Jean-Louis G, Professor of Population Health, Center for Healthful Behavior Change, Department of Population Health, New York University School of Medicine, 227 East $30^{\text {th }}$ Street, $6^{\text {th }}$ Floor, New York, USA, Fax: 212.263.4201, Tel: 646.501.2623, E-mail: girardin.jean-louis@nyumc.org

Citation: Rogers A, Ravenell J, Donat M, Sexias A, Ogedegbe C, et al. (2015) Predictors of Obstructive Sleep Apnea Risk among Blacks with Metabolic Syndrome. J Obes Overweig 1(1): 104. doi: 10.15744/24557633.1.104

\section{Received Date: January 02, 2015 Accepted Date: May 21, 2015 Published Date: May 27, 2015}

\begin{abstract}
Introduction: Identification of risk factors for obstructive sleep apnea (OSA) is important to enable comprehensive intervention to reduce OSA-related cardiovascular disease (CVD). The metabolic syndrome outcome study (MetSO) provides a unique opportunity to address these factors. This study investigated risk of OSA among blacks with metabolic syndrome.

Methods: The present study utilized data from MetSO, an NIH-funded cohort study of blacks with metabolic syndrome. A total of 1,035 patients provided data for the analysis. These included sociodemographic factors, health risks, and medical history. Physiciandiagnosed conditions were obtained using an electronic medical record system (Allscripts, Sunrise Enterprise). Patients were diagnosed with metabolic syndrome using criteria articulated in the joint interim statement for harmonizing the metabolic syndrome. Patients with a score $\geq 6$ on the Apnea Risk Evaluation System (ARES) questionnaire were considered at risk for OSA. Obesity is defined by body mass index (BMI $\left.\geq 30 \mathrm{~kg} / \mathrm{m}^{2}\right)$

Results: Of the 1,035 patients screened in the MetSO cohort, $48.9 \%$ were at high risk for OSA. Using multivariate-adjusted logistic regression analysis, we observed that obesity was the strongest predictor of OSA risk $(\mathrm{OR}=1.59,95 \% \mathrm{CI}=1.24-2.04, \mathrm{p}<0.0001)$. This finding remained significant even after adjustment for known covariates including blood pressure, low-density lipoprotein, highdensity lipoprotein, and glucose levels $(\mathrm{OR}=1.44,95 \% \mathrm{CI}=1.11-1.86, \mathrm{p}<0.001)$.

Conclusion: Blacks in the MetSO cohort are at greater OSA risk, relative to the adult population in developed countries. Consistent with previous observations, obesity proved the strongest independent predictor of OSA risk among blacks with metabolic syndrome.

Keywords: Obstructive sleep apnea; Metabolic syndrome; Obesity; Blacks
\end{abstract}

\section{Introduction}

Obstructive sleep apnea (OSA) is characterized by recurring sleep disruptions, intermittent hypercapnia and hypoxia, resulting in increased sympathetic nerve activity, oxidative stress and hemodynamic changes [1,2]. Oxidative stress has been shown to reduce vasodilatation and increase platelet adhesion, leading to metabolic dysfunction, systemic inflammation, and hypercoagulation [3]. OSA has also been associated with obesity, insulin resistance and metabolic syndrome [4,5], which is characterized by a constellation of cardio-metabolic risk factors (i.e., obesity, hypertension hyperlipidemia and diabetes), that are associated with adverse cardiovascular outcomes [6,7]. The term Syndrome $Z$ has been coined to explain the combination of interrelated diseases in recent sleep literature [8]. Syndrome $\mathrm{Z}$ includes metabolic syndrome features of increased waist circumference, hypertension, diabetes, dyslipidemia, the incorporation of sleep apnea [8].

Despite evidence that OSA is associated with metabolic syndrome as well as its components [9], little is known about OSA risk among blacks with a diagnosis of metabolic syndrome, although previous studies have suggested that they are generally at higher risk for OSA [10]. Understanding the mechanisms underlying the higher prevalence of OSA among blacks with associated cardio-metabolic risk factors is important in elucidating the relationship between OSA and metabolic syndrome. Thus, we sought to (1) assess OSA risk among blacks with metabolic syndrome and (2) explore cardio-metabolic predictors of OSA risk in this vulnerable population. 


\section{Methods}

Data was collected as part of the metabolic syndrome outcome study (MetSO) an on-going study of blacks with metabolic syndrome in Brooklyn, New York. A total of 1,035 patients provided data for the analysis. These included sociodemographic factors, health risks, and medical history. Physician-diagnosed conditions were obtained using an electronic medical record system (Allscripts, Sunrise Enterprise). Patients were diagnosed with metabolic syndrome using the National Heart, Lung and Blood Institute and the American Heart Association guidelines [11]. According to these guidelines, metabolic syndrome is diagnosed when a patient has at least three of the following five conditions: fasting glucose $\geq 100 \mathrm{mg} / \mathrm{dl}$ or receiving treatment for hyperglycemia, blood pressure $\geq 130 / 85 \mathrm{~mm} \mathrm{Hg}$ or receiving drug therapy for hypertension, triglycerides $\geq 150 \mathrm{mg} / \mathrm{dl}$ or receiving drug treatment for hypertriglyceridemia, HDL-C $<40 \mathrm{mg} / \mathrm{dl}$ in men or $<50 \mathrm{mg} / \mathrm{dl}$ in women or receiving drug therapy for HDL-C and a waist circumference $\geq 102 \mathrm{~cm}$ (40 in) in men or $\geq 88 \mathrm{~cm}$ (35 in) in women.

Patients were also assessed for OSA risk using the Apnea Risk Evaluation System (ARES), individuals with an ARES score $\geq 6$ were considered at risk for OSA. We used ARES to identify individuals who were at OSA risk because of its accuracy in evaluating populations with a large pretest of OSA probability. Data solicited included sociodemographics, diseases associated with OSA, the Epworth Sleepiness Scale, and frequency of breathing abnormalities. The questionnaire has a sensitivity of 0.94 , specificity of 0.79 (based on a clinical cut-off of AHI > 5), positive predictive value of 0.91 and negative predictive value of 0.86 [2]. Our rationale for using the ARES questionnaire is also based on our previous experience. In the last 4 years, we have screened 1,250 black patients in primary-care settings and 150 blacks in the community with no documented refusals $[2,12,13]$. The institutional review boards (IRB) at SUNY Downstate Medical Center (protocol \# 09-193) approved this study prior to implementation.

\section{Statistical Analysis}

Frequency and measures of central tendency were used to describe the sample. In preliminary analyses, Pearson and Spearman correlations were used to explore relationships between variables of interest. To determine the best cardio-metabolic predictor of OSA risk among blacks with metabolic syndrome, we utilized multivariate-adjusted logistic regression modeling. Covariates entered in the model were age, sex, and income. Before constructing the model, correlational analyses were performed to assess associations between hypothesized predictors (i.e., obesity defined as BMI $\geq 30 \mathrm{~kg} / \mathrm{m}^{2}$, hypertension, dyslipidemia, and diabetes) and the dependent variable (i.e., OSA risk). In preliminary analyses, these factors were associated with the main predictor (BMI) and the dependent variable (OSA risk).

\section{Results}

A total of 1,035 patients with metabolic syndrome provided data for this study. The average age of the sample was $62 \pm 14$ years (range: $20-97$ years); $71 \%$ were female and $43 \%$ reported an annual income lower than $\$ 10 \mathrm{~K}$. Of the sample, $93 \%$ were diagnosed with hypertension; $61 \%$, diabetes; $72 \%$, dyslipidemia; $90 \%$ were overweight/obese; $33 \%$ had a history of heart disease and $10 \%$ had a stroke. ARES data indicated that $48 \%$ were at high OSA risk. Descriptive characteristics of cardio-metabolic parameters are presented in Table 1.

\begin{tabular}{|c|c|c|}
\hline Variable & Mean & SD \\
\hline Systolic BP & $134.98 \mathrm{~mm} / \mathrm{hg}$ & $16.39 \mathrm{~mm} / \mathrm{hg}$ \\
\hline Diastolic BP & $75.77 \mathrm{~mm} / \mathrm{hg}$ & $10.55 \mathrm{~mm} / \mathrm{hg}$ \\
\hline LDL Cholesterol & $105.6 \mathrm{mg} / \mathrm{dL}$ & $36.88 \mathrm{mg} / \mathrm{dL}$ \\
\hline HDL Cholesterol & $48.03 \mathrm{mg} / \mathrm{dL}$ & $16.49 \mathrm{mg} / \mathrm{dL}$ \\
\hline Triglycerides & $134.98 \mathrm{mg} / \mathrm{dL}$ & $73.24 \mathrm{mg} / \mathrm{dL}$ \\
\hline Glucose & $138.38 \mathrm{mg} / \mathrm{dL}$ & $68.27 \mathrm{mg} / \mathrm{dL}$ \\
\hline HbAlc & $7.93 \%$ & $1.63 \%$ \\
\hline
\end{tabular}

Note: $\mathrm{BP}=$ Blood Pressure; $\mathrm{LDL}=$ Low-density lipoprotein,

$\mathrm{HDL}=$ High-density lipoprotein; $\mathrm{HbAlc}=$ glycated hemoglobin

Table 1: Metabolic characteristics of the study participants

Using multivariate logistic regression analysis, adjusting for age sex, and income, we observed that obesity was the strongest predictor of OSA risk $(\mathrm{OR}=1.59,95 \% \mathrm{CI}=1.24-2.04, \mathrm{p}<0.0001)$. This finding remained significant even after adjustment for blood pressure, low-density lipoprotein, high-density lipoprotein, and glucose levels $(\mathrm{OR}=1.44,95 \% \mathrm{CI}=1.11-1.86, \mathrm{p}<0.001)$. Descriptive characteristics of a t-test p-value between risk group and non-risk group obesity parameters are presented in Table 2 . 


\begin{tabular}{|c|c|c|c|}
\hline Variables & OSA risk & No OSA risk & Fisher Exact Significance $(p$ value $)$ \\
\hline Insulin/Glucose & $48.6 \%$ & $51.4 \%$ & N.S. \\
\hline Dyslipidemia & $48.6 \%$ & $51.4 \%$ & N.S. \\
\hline Elevated BP/Hypertension (>130/85) & $49.2 \%$ & $50.8 \%$ & .039 \\
\hline BMI Male & $51.4 \%$ & $48.6 \%$ & .059 \\
\hline BMI Female & $49.6 \%$ & $50.4 \%$ & \\
\hline
\end{tabular}

Insulin/Glucose=Fasting plasma glucose $>110 \mathrm{mg} / \mathrm{dL}$; Dyslipidemia=Plasma triglycerides $>150 \mathrm{mg} / \mathrm{dL}, \mathrm{HDL}$ cholesterol $<40 \mathrm{mg} / \mathrm{dL}$ in men and $<50 \mathrm{mg} / \mathrm{dL}$ in women; Elevated $\mathrm{BP} /$ Hypertension=BP medication or $\mathrm{BP}>130 / 85 \mathrm{~mm} / \mathrm{Hg}$; BMI Overweight-Obese $>25$

Table 2: Cross-Tab with MetS indicators of OSA risk

\section{Discussion}

Using data from the Metabolic Syndrome Outcome Study, the largest cohort of blacks with metabolic syndrome, we found that $48 \%$ of the patients were at high OSA risk, which exceeds OSA risk observed in the general US population [14]. Equally important, results of this study showed that obesity is the strongest predictor of OSA risk among blacks with a diagnosis of metabolic syndrome.

While we could not determine how many of at-risk patients would actually receive an OSA diagnosis, we are guided by available data showing that among patients with metabolic syndrome referred for OSA assessment, 50.1\% received a diagnosis [15]. We surmise that this might even be greater among blacks with metabolic syndrome. In other patient care settings where primary care is sought, like the Emergency Department (ED), we found a dearth of literature describing any patients with metabolic syndrome being referred for OSA screening. Available literature suggests that ED patients who do not regularly see a primary-care provider or have no primary-care provider are particularly at risk for undiagnosed OSA. Emergency physicians can play an important role in recognizing patients at risk for OSA, referring them for further diagnostic work-up, and offering recommendations from the ED [16]. Indeed, in one of our studies conducted among blacks referred from primary-care clinics for lab-based sleep assessment, 91\% received an OSA diagnosis [17]. In all, these data suggest blacks with metabolic syndrome and who are at risk for OSA should be aggressively referred for OSA assessment and treatment, given evidence that OSA treatment reduces negative CVD outcomes associated with metabolic syndrome.[14] Evidence has indicated that OSA treatment with continuous airway pressure for 5.8 hours or longer is associated with reductions in diastolic and systolic blood pressures, resulting in a decrease of hypertension by suppressing sympathetic activity [18]. Data from a similar study, the Heart Biomarker Evaluation in Apnea Treatment (HeartBeat), also yielded similar findings. Investigators of that study, assessing effects of CPAP verses supplemental oxygen therapy in reducing CVD risk among high-risk patients with OSA, showed a decrease in mean arterial blood pressure and C-reactive protein with CPAP [19].

The finding that obesity was the strongest predictor of OSA risk is consistent with previous research, although this represents a unique cohort of black patients. Available data suggest that individuals experiencing a $10 \%$ gain in weight had a six-fold increased odds of developing OSA [20,21]. Furthermore, for every $6 \mathrm{~kg} / \mathrm{m}^{2}$ increase in BMI, risk of developing OSA increases fourfold [22]. Thus, obesity, whether assessed through BMI or waist circumference, may indeed be the common factor that is associated with increased risk of OSA and metabolic syndrome. We should also note that emerging clinical evidence reveals metabolic syndrome itself may have unique effects on the development of OSA, and that sleep apnea may be a manifestation of metabolic syndrome [23-25].

The impetus for investigating associations between obesity and OSA among blacks with metabolic syndrome was supported by evidence that obesity is more prevalent among blacks compared with any other ethnic group in the United States [26]. Data from the Cleveland family study, a cohort of 277 African-Americans participants representing 59 different lines of ancestry in a genome scan linkage suggested a genetic link in the comorbidity of obesity and OSA among blacks [27]. Specifically, linkage analysis revealed that the heritability of BMI and AHI (apnea-hypopnea index used to diagnose OSA) was $54 \%$ and $34 \%$, respectively. When viewed in the context of the studies referenced above, our study highlights the need for sustained effort to focus on black patients, who are often at a clinical disadvantage due to lack of representation in clinical studies, undiagnosed OSA, lack of patient awareness and knowledge of the implications of obesity [28]. A better understanding of the factors underlying relationships between obesity and OSA among blacks may have important public health implications regarding CVD risk-reduction interventions for this underserved population.

\section{Conclusion}

The finding that $48 \%$ of the patients were at high OSA risk is important, suggesting that OSA risk is greater among blacks with metabolic syndrome. It is of interest to assess whether similar observations would be made in a population of healthy individuals.

\section{Limitations}

An important limitation of the study relates to the unavailability of a diagnosis of OSA. Such information would have permitted the determination of the magnitude of associations of OSA with metabolic parameters such as insulin resistance [6]. This may also help elucidate relationships of dysglycemia and OSA. 


\section{Acknowledgement}

This research was supported by funding from the National Institutes of Health: R01MD007716, R01HL095799, RO1MD004113, U54NS081765 and K24HL2222315. The funding source had no role in the design, conduct, or analysis of the study, or in the decision to submit the manuscript for publication.

\section{References}

1. Adedayo AM, Olafiranye O, Smith D, Hill A, Zizi F, et al. (2014) Obstructive sleep apnea and dyslipidemia: evidence and underlying mechanism. Sleep Breath 18: $13-8$.

2. Levendowski DJ, Olmstead R, Popovich D, Carper DL, Berka C, et al. (2007) Assessment of Obstructive Sleep Apnea Risk and Severity in Truck Drivers: Validation of a Evaluation Questionnaire. Sleep Diag Therapy 2: 20-26.

3. Vijayan VK (2012) Morbidities associated with obstructive sleep apnea. Expert Rev Respir Med 6: 557-66.

4. Rajagopalan N (2014) Obstructive Sleep Apnea: Not just a Sleep Disorder. J Postgrad Med 57: 168-75.

5. Nevin MA (2013) Pediatric Obesity, Metabolic Syndrome, and Obstructive Sleep Apnea Syndrome. Pediatric annals 42: 205-10.

6. Drager LF, Togeiro SM, Polotsky VY, Lorenzi-Filho G (2013) Obstructive sleep apnea: a cardiometabolic risk in obesity and the metabolic syndrome. J American College Cardiol 62: 569-76.

7. Wilcox I, McNamara S, Collins F, Grunstein R, Sullivan C (1998) "Syndrome Z”: the interaction of sleep apnoea, vascular risk factors and heart disease. Thorax 53: S25-8.

8. Jean-Louis G, Zizi F, Clark LT, Brown CD, McFarlane SI (2008) Obstructive sleep apnea and cardiovascular disease: role of the metabolic syndrome and its components. J Clin Sleep Med 4: 261-72.

9. Jean-Louis G, Zizi F, Brown D, Ogedegbe G, Borer J, et al. (2009) Obstructive sleep apnea and cardiovascular disease: evidence and underlying mechanisms. Minerva Pneumol 48: 277-93.

10. Jean-Louis G, Zizi F, Casimir G, DiPalma J, Mukherji R (2005) Sleep-disordered breathing and hypertension among African Americans. J Human Hyperten 19: 485-90.

11. Grundy SM, Cleeman JI, Daniels SR, Donato KA, Eckel RH, et al. (2005) Diagnosis and management of the metabolic syndrome: an American Heart Association/National Heart, Lung, and Blood Institute Scientific Statement. Circulation 112: 2735-52.

12. Pandey A, Gekhman D, Odigie P, Louis GJ (2011) T-I-071 Short sleep and dysfunctional beliefs and attitudes toward sleep among black men. Sleep Breathing Disorders 12: S77.

13. Benoit J, Pandey A, Racine C, Zizi F, Francois A, et al. (2012) Differences in Sleep Measures between Caribbean and US-Born Blacks with Metabolic Syndrome. Amer Acad Sleep Med 35: 305.

14. Olafiranye O, Akinboboye O, Mitchell JE, Ogedegbe G, Jean-Louis G (2013) Obstructive sleep apnea and cardiovascular disease in blacks: a call to action from the Association of Black Cardiologists. Am Heart J 165: 468-76.

15. Meslier N, Gagnadoux F, Giraud P, Person C, Ouksel H, et al. (2003) Impaired glucose-insulin metabolism in males with obstructive sleep apnoea syndrome. Eup Respiratory J 22: 156-60.

16. Vearrier D, Phillips B, Greenberg MI (2011) Addressing obstructive sleep apnea in the emergency department. J Emerg Med 41: 728-40.

17. Jean-Louis G, von Gizycki H, Zizi F, Dharawat A, Lazar JM, et al. (2008) Evaluation of sleep apnea in a sample of black patients. J Clin Sleep Med 4: 421-5.

18. Demede M, Pandey A, Zizi F, Bachmann R, Donat M, et al. (2011) Resistant hypertension and obstructive sleep apnea in the primary-care setting. Int J Hypertension Article ID 340929: 1-5.

19. Gottlieb DJ, Punjabi NM, Mehra R, Patel SR, Quan SF, et al. (2014) CPAP versus oxygen in obstructive sleep apnea. N Engl J Med 370: 2276-85.

20. Young T, Shahar E, Nieto FJ, Redline S, Newman AB, et al. (2002) Predictors of sleep-disordered breathing in community-dwelling adults: the Sleep Heart Health Study. Arch Intern Med 162: 893-900.

21. Peppard PE, Young T, Palta M, Dempsey J, Skatrud J (2000) Longitudinal study of moderate weight change and sleep-disordered breathing. JAMA 284: 3015-21.

22. Vgontzas AN, Bixler EO, Chrousos GP (2003) Metabolic disturbances in obesity versus sleep apnea: the importance of visceral obesity and insulin resistance. J Intern Med 254: 32-44.

23. Vgontzas AN, Bixler EO, Chrousos GP (2005) Sleep apnea is a manifestation of the metabolic syndrome. Sleep Med Rev 9: 211-24.

24. Kono M, Tatsumi K, Saibara T, Nakamura A, Tanabe N, et al. (2007) Obstructive sleep apnea syndrome is associated with some components of metabolic syndrome. Chest J 131: 1387-92.

25. Coughlin SR, Mawdsley L, Mugarza JA, Calverley PMA, Wilding JPH (2004) Obstructive sleep apnoea is independently associated with an increased prevalence of metabolic syndrome. Eup Heart J 25: 735-41.

26. Pan L, Galuska DA, Sherry B, Hunter AS, Rutledge GE, et al. (2009) Differences in Prevalence of Obesity among Black, White, and Hispanic Adults - United States, 2006-2008. J Morbidity and Mortality Weekly Report 58: 740-4.

27. Palmer LJ, Buxbaum SG, Larkin EK, Patel SR, Elston RC, et al. (2004) Whole genome scan for obstructive sleep apnea and obesity in African-American families. American J Respiratory Critical Care Med 169: 1314-21.

28. Shaw R, McKenzie S, Taylor T, Olafiranye O, Boutin-Foster C, et al. (2012) Beliefs and attitudes toward obstructive sleep apnea evaluation and treatment among blacks. J Natl Med Assoc 104: 510-9. 


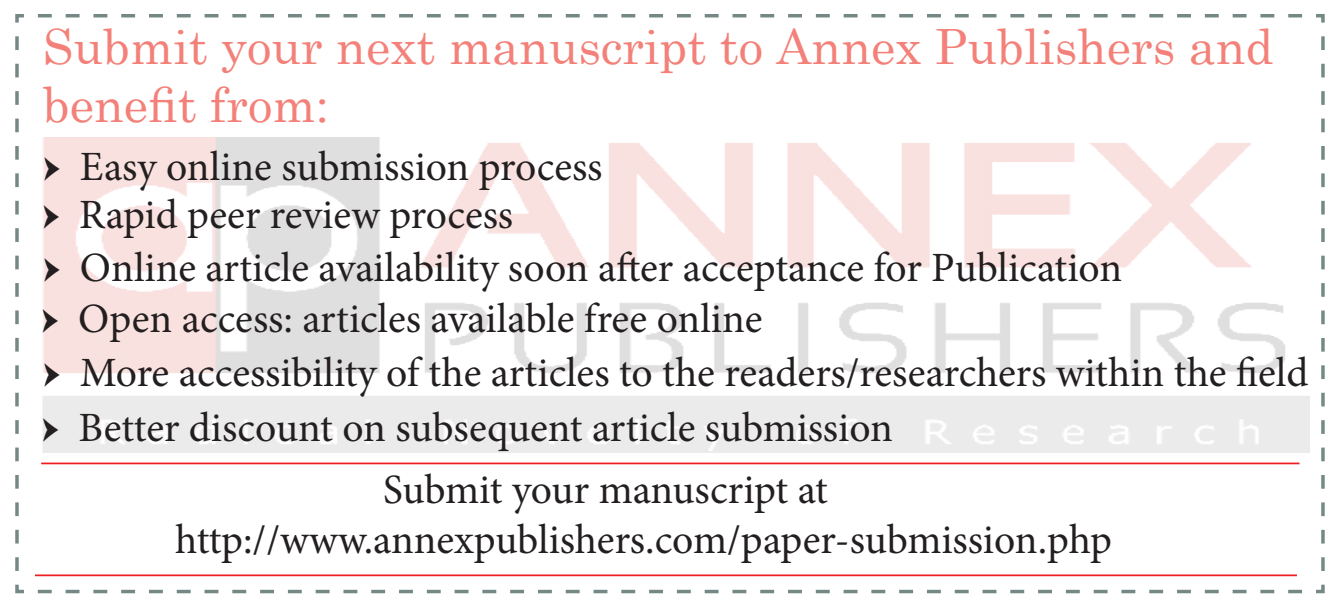

